\title{
Isolated anterior cervical hypertrichosis
}

INSERM

\section{Source}

INSERM. (1999). Orphanet: an online rare disease and orphan drug data base. Isolated anterior cervical hypertrichosis. ORPHA:3387

Anterior cervical hypertrichosis is a rare form of localised hypertrichosis characterised by hair growth near the laryngeal prominence during childhood. 